\title{
Alain Stan: Le poète joue. ORF-CD 3197, LC11428, 2015.
}

Nach den 2007 und 2010 veröffentlichten Alben Terres du Ciel (2007) und La musique a son mot à dire (2010) legt Alain Stan, alias Alain Driguès, mit Le poète joue (2015) seine dritte unter dem Ö1-Label produzierte CD vor. Bereits 2002 war Étrange Planète (Hoanzl) erschienen und weitere fünf Jahre zuvor (1997) sein im Verlag Der Apfel publiziertes Buch BerufAusländer, in dem der Wahlösterreicher in „eine[m] Falschesdeutsch “ (www.alainstan.at) ${ }^{1}$ bzw. Französisch-Wienerisch eine der großen Schwächen des Gastlandes, die unterschwellige Angst vor dem Fremden, aufs Korn nimmt.

Doch wer ist Alain Stan? Eva Allerstorfer bringt es auf den Punkt: Der Schauspieler, Regisseur, Theaterautor, Straßenkünstler, auteur-compositeur-interprète etc. ist zu Beginn der 1950er Jahre „,in Algier geboren, in Frankreich aufgewachsen, in der Welt groß geworden und nun in Vorchdorf zu Hause" (Allerstorfer 2011). Er hat zwar immer schon Musik gemacht - in den 1970er Jahren in der Metro von Paris, dann am Forum des Halles -, im Zentrum seines künstlerischen Engagements stand jedoch bis etwa 2003 sein 1984 in Bordeaux gegründetes Thêâtre de l'instant, von dem sich auch sein Künstlername Alain Stan - à l'instant - ableitet. Wenige, nur scheinbar harmlose Requisiten, exzellente, in Paris und Berlin erlernte Pantomime, ein unermüdliches Spielen und Infragestellen des „ganz normalen Alltags" mit seinen falschen Fassaden und Ungereimtheiten - das ist sein Markenzeichen und es überrascht nicht, dass der Künstler, der in den frühen 1990er Jahren das Komitee „Rettet die Straßenkunst“ gegründet hat, 1991 und auch noch danach ${ }^{2}$ in Wien immer wieder mit einem Auftrittsverbot belegt wurde.

Ist Alain Stan somit ein engagierter auteur-compositeur-interprète? Die Antwort ist diffizil: bis zu einem gewissen Grad ja, auf seine ganz besondere Weise, aber sicher nicht in einem konkreten politischen Sinn. Denn wie der Titel des Albums verrät, sieht sich Alain Stan in seinen Chansons vor allem als poète, und zwar als poète, der in einer langen Tradition steht. In seinen Chansons geht das lyrische Ich auf Distanz zum biographischen Ich; der Text hat besonderes Gewicht, denn der Künstler will dem Publikum durchaus Inhalte vermitteln; die Musik wiederum, auch wenn keineswegs simpel, dient dem Wort und der emotionalen Kommunikation. Thematisch greift der Künstler unterschiedliche Fäden auf. Da ist zunächst die Weltsicht der Romantik und Spätromantik, sprich der Symbolisten, bis hin zur „Art poétique“ von Verlaine und dem „Voyant" von Rimbaud. Da sind auch die Derbheit und die Ironie eines Brassens, Ferré und Co, mit durchaus wahrnehmbaren Anklängen an Villon. Da sind schließlich Überlagerungen mit aktuellen Problematiken wie Drogensucht oder Nationalismus und nicht zuletzt zeitgenössische apokalyptische Visionen, die das (spät)romantische Lebensgefühl in die illusionslose Postmoderne hinüberziehen. Oder gibt es Hoffnung? Das Lied 15, „La la la“, mit seiner Reduktion des Textes auf einen Kindervers, 
mit seiner sangbaren Melodie, seinen Kinderstimmen - ein Lied, das dem Hörer zunächst völlig unpassend erscheint - rundet die CD thematisch ab und lädt ein, über ihre Struktur nachzudenken. Oder handelt es sich lediglich um eine Reminiszenz an Charles Trenets „L'âme des poètes“ aus dem Jahr 1951, mit der sich der auteur-compositeur-interprète von heute tröstet? Heißt es doch bei Trenet: „Longtemps, longtemps, longtemps / Après que les poètes ont disparu / Leurs chansons courent encore dans les rues [...]/ On fait la la la la la la [...]. " Selbst der Titel des Albums fände so seine Erklärung.

Doch zurück zum strukturellen Argument. Die CD wird durch vier Instrumentalstücke von Thomas Nickel untergliedert, deren Titel - wieder ganz in (spät)romantischsymbolistischer Manier - die Idee der Reise und der Jahreszeiten aufgreifen. Lediglich die Reihenfolge überrascht, denn nicht Frühling-Sommer-Herbst-Winter oder SommerHerbst-Winter-Frühling werden evoziert, sondern in innerer Überkreuzung SommerHerbst-Frühling-Winter. Der beruhigende Zyklus der Jahreszeiten ist somit durchbrochen, und doch ist mit „l'été [l'hiver] recommencé - die Untertitel der Musikstücke - auch von Wiederkehr die Rede. Wie das zyklische Prinzip Bruchlinien zeigt, bleibt schließlich auch der ,apokalyptische Endzustand', den unsere Gesellschaften im 21. Jahrhundert erreicht haben und der mehrere Chansons ${ }^{3}$ prägt, nicht unwidersprochen: Die Apokalypse wird eben durch das Singen der Kinder in „La la la“ neutralisiert, während das letzte ,Herbstlied“ - „Le poète joue“ (Nummer 9) - nach dem abschließenden Instrumentalteil „Voyage, l'hiver recommencé" noch ein zweites Mal aufgegriffen wird (Nummer 17). Im Fluss von Kontinuität und Bruch unterstreicht diese Reprise die Botschaft des Künstlers, die sich als postmodern relativiertes Herzstück des Albums erweist. Das Spannungsfeld von Bruch und Kontinuität schöpft übrigens auch das Coverbild aus, ein Gemälde von Annie Driguès, der Schwester des Künstlers: In ihm dialogieren mit Gelb, Rot und Schwarz die Farben der Apokalypse und des Lebens, es dialogieren aber auch Masken und Schiffe als Metaphern der Starre und der Bewegung.

Doch werfen wir einen detaillierteren Blick auf die Chansons. Das Album beginnt mit „Capitaine solitaire“ (Nummer 2), einem Chanson, in dem sich das lyrische Ich als einsamer Kapitän auf einem Stück Holz auf eine gefährliche Seefahrt begibt: unvorbereitet, ohne dass ihm jemand gezeigt hätte, wie man das Steuer hält, in die Existenz geworfen, mit den Elementen ringend. „La tempête fait rage, / Ne perds pas ton courage“, wirft der Sänger hors texte ein. Dieses Ich, das sich seiner Vergänglichkeit bewusst ist und gewissermaßen sein Außenseitertum zelebriert, wenn es sich fern wähnt von Hass und Vergnügungssucht der „cités maladroites“, erinnert den Hörer unweigerlich an die berühmte „Canción del pirata“ (1830) des spanischen Romantikers José de Espronceda, dessen Schiff „sin temor“ den Naturgewalten trotzt und das Ich Freiheit finden lässt. Baudelaire mit seinem Gedicht „Le Léthé, das auch von Ferré interpretiert wurde, ist unterschwellig präsent, wenn Alain Stan im nächsten Chanson „Au rivage du Léthé“ (Nummer 3) erneut Vergänglichkeit, Unabänderlichkeit, aber auch die Verdrängung des Unabänderlichen anspricht: „Au rivage du Léthé, le monde a oublié“, heißt es in einem der seltenen Refrains des auteur-compositeur-interprète. Aber auch der sehr poetische (und einzige) Text von Annie Driguès, „La ville“ (Nummer 4), erinnert 
den Hörer unweigerlich daran, dass es in Baudelaires Fleurs du Mal ,Stadtbilder ' gibt. „La ville" ist einer jener Texte, die Alain Stan rezitiert und nicht singt und der besonders durch seine Schlichtheit beeindruckt. Isotopien der Stadtdarstellung, bis hin zur Anonymität und Indifferenz des Städters, verbinden sich mit Begriffen der Natur und Körperlichkeit und verweisen zugleich auf Camus' Kette des Absurden boulot - métro - dodo.

Mit „Le sens de l'amour“ (Nummer 6) gelingt Alain Stan ein unvergleichlich schönes Lied über den Fortbestand der Liebe, die jenseits von Alterungs- und Reifungsprozessen, jenseits von Ängsten in der Erinnerung siegreich aufersteht. Wie Brassens in „La mauvaise réputation" (1952), nur keineswegs ironisch, spielt der Künstler hier mit der sinnlichen Wirklichkeit: Selbst wenn sich das Ich als ,blind', stumm', ,taub' und ,weit weg' beschreibt, wird seine Liebe das Du ,sehen', zu ihm ,sprechen', es ,hören' und ,umarmen'. Einen ganz anderen Ton schlagen die folgenden beiden Chansons an, die Beispiele dafür liefern, was ich als „Derbheit und die Ironie eines Brassens, Ferré und Co“ bezeichnet habe. In „Rendezvous" (Nummer 7) - bestehend aus 15 (annähernden) 24-Silblern, als wollte sich das Ich endlos dem ,Treffen` entziehen - erzählt es, während es auf einen Bus wartet, dem mittelalterlich personifizierten Tod von seinem Plan, seinen Körper mit Haut und Haar dem kreuchenden Getier, der "gente [sic] non humaine“, zu vermachen. Bis dahin aber macht es sich aus dem Staub, nicht ohne den Hörer mit dem Gefühl eines Déjà-Vu zurückzulassen. Wie hieß es doch in François Villons „Ballade des pendus“?

Aber auch "Le président, le prêtre et le procureur" (Nummer 8) erinnert an Brassens und die für die restaurative Nachkriegszeit so typische Institutionsschelte. Die hochwohlgeborenen Vertreter von Staat, Kirche und Gerichtsbarkeit entpuppen sich als Drogensüchtiger, Zuhälter und Kinderschänder - wer dächte da nicht an „Le Gorille“-, während sich das lyrische Ich mit einem einfachen „sauter [1]a femme [du procureur] " zufrieden gibt. Das letzte Chanson vor dem Instrumentalstück „Voyage, le printemps écarlate“ ist mit dem Titel des Albums eponym (Nummer 9) und führt zurück zu jenen poètes, von denen Ferré seinerzeit „les papiers!“ eingefordert hatte: Der Dichter riskiert schachspielend Leben und Tod, blickt als ,voyant ' hinter die Kulissen und sagt in Verlaine'scher Manier „l'indicible sans l'avoir prononcé“. Der poète ist schließlich ein Meister der Metapher und Alain Stans Metaphern sind neu und originell. In seiner Welt geht nicht der Eiffelturm spazieren wie bei Trenet, aber es geschehen wundersame Dinge, die wohl manchmal der interkulturellen Erfahrung des Künstlers geschuldet sind:

Une tempête de neige enfante le désert, une montagne surgit de mers inconnues, une avalanche se met à rebrousser chemin et la foudre reste muette quand le glacier s'enflamme (Nummer 9 und Nummer 17)

Nicht umsonst lässt der auteur-compositeur-interprète das Album mit genau diesen Versen enden (Nummer 17). 
Die letzte Gruppierung von Chansons, die Nummern 11 bis 13, zeigt apokalyptische und zugleich konkret zeitgenössische Bezüge. Bereits der Mann mit dem „Visage de brume" (Nummer 11) ist mehr als ein Obdachloser, frierend der Straße ausgesetzt. Es handelt sich auch um existentielle Obdachlosigkeit, die schmerzhaft auf die Gefühllosigkeit der Welt trifft: Die Städte ,mähen' nieder, ihre Kreuzungen schneiden wie Klingen, Sirenen hämmern Litaneien. Noch dramatischer das Szenario des Chansons „Le souffle des anges“ (Nummer 12): Hier führen den Hörer grauenvolle, doch zumeist sehr originelle Bilder in eine halluzinatorische Welt: Es ,hämmert' in Augen und Ohren, Glassplitter bedecken das Trottoir, Phantome, verstümmelte Körper, die Luft mit Erde gefüllt, die zögerliche Bleifigur droht zu stürzen. Gewiss, auch Baudelaires lyrisches Ich konnte in „Spleen“ (1857) klagen, doch dieser neue spleen hat eine neue Qualität. Er beruhigt sich zwar in „Vagues“ (Nummer 13) zu einem Refrain, der mit gewissem Stolz dem Ende trotzt - „La vie n'est plus, mais elle continue / dans un passage fier entre terre, ciel et mer“ -, „meurtritudes“ und „enfer de la peine" aber bleiben. Das letzte Chanson „À l'ombre de la lumière“ (Nummer 14) schließlich wird konkret, wenn es mit den Symbolen Kreuz (Christen), Stern (Juden, Muslime) und Flagge (Nationalisten) jene ,großen Erzählungen' evoziert, in deren Schatten Gewalt und Tod gedeihen. Im Schatten der Flaggen wächst ein „état de guerre latent“, dem der Blick auf das „kaléidoscope des terres et des cieux" verwehrt bleibt, und beim ,Sonnenuntergang der Menschheit 'werden die Symbole stumm daran erinnern, dass niemand mehr das Licht feiern kann.

Alain Stan erschafft in seiner letzten CD ein poetisches Universum, das ohne die ,Dichter vor ihm' nicht denkbar wäre, ja gerade aus dem Spiel mit den vielfältigen Formen der Intertextualität seine Originalität bezieht. Es würde zu weit führen, hier auf die poetische Sprache des auteur-compositeur-interprète einzugehen. Es sei nur so viel gesagt, dass Verlaines „De la musique avant tout chose“ in Reim, Binnenreim, Homophonie etc. auf Schritt und Tritt spürbar bleibt. Was den Rhythmus anlangt, so sei nicht nur auf die so häufige Kombination unterschiedlich langer Strophen verwiesen, sondern auch auf stropheninterne Phänomene wie die Isometrie. Schon auf dem Papier ist sie keineswegs der Normalfall; im Vortrag jedoch weicht sie einem dynamischen Spiel von Akzentuierungen und Pausen, und dies auch dort, wo der Künstler für Rezitation oder Sprechgesang optiert. Die Stimme ist für Alain Stan zentral, er lässt ihrem ,souffle‘ freien Lauf.

Für den Komponisten und Musiker wiederum lässt sich der aus der Opernwelt bekannte Leitspruch „Prima le parole e dopo la musica“ bemühen, und doch ist Alain Stans Musik keineswegs monoton. Sie hilft dem Interpreten inhaltliche Akzente zu setzen. Klavier, Gitarre, aber auch Keyboard und Melodica erlauben eine breite musikalische Farbgebung, wobei Stan mit verschiedenen Kunstgriffen operiert: ein Ende, das nach harmonischer Auflösung drängt, der Wechsel von Dur nach Moll, Chromatik, Dissonanzen, Polyrhythmik, Melodiefragmente, die Wirklichkeit zu imitieren suchen, Beschleunigung, Ritardando, Crescendo und vieles mehr. Alles in allem ist die vorliegende $C D$ ein gelungenes künstlerisches Ganzes, in dem viele Fäden der klassischen Chansontradition zusammenlaufen und zugleich eigenständig weitergesponnen werden. 
Zum Schluss sei eine letzte, kritische Anmerkung gestattet: Ob auf der Bühne oder im Textheft, Alain Stan legt Wert darauf, dass dem Hörer der Text auch in deutscher Übersetzung vorliegt. Anders als beim gewollten „Falschesdeutsch“ des Komikers geht es hier jedoch darum, ein höchst poetisches Universum in einer anderen Sprache erstehen zu lassen, und dies gelingt leider nicht. Übersetzungsfehler, syntaktische Probleme, aber auch das Verfehlen der Tonlage in der Zielsprache machen die Übersetzung nicht zum Genuss und verweisen den Hörer zurück auf das Original.

\section{Ursula MATHIS-MOSER (Innsbruck)}

\section{Endnoten}

1 Cf. Biographie, Foto 78, „Völlig bodenlos“, 1995_wien_auto_revue.jpg.

22001 etwa mit seinem Programm „Der Ausländer, der fremd ging“. Cf. http://www.alainstan.at/ (Zugriff 27.12.2016).

3 Unter anderem „Le souffle des anges“ aus dem Abschnitt „Le printemps écarlate“.

\section{Bibliographie}

Allerstorfer, Eva: „Ein französisches Statement“. In: OÖ Nachrichten (Februar 2011), http://www. alainstan.at/ (Zugriff 27.12.2016).

Stan, Alain: http://www.alainstan.at/ (Zugriff 27.12.2016). 